\title{
Opposite Hydrogen Behaviors in GaAsN and InAsN Alloys: Band Gap Opening Versus Donor Doping
}

\author{
Francesco Filippone,* Giuseppe Mattioli, Antonio Polimeni, Marco Felici, and Aldo Amore Bonapasta
}

Cite This: J. Phys. Chem. C 2020, 124, 19240-19251
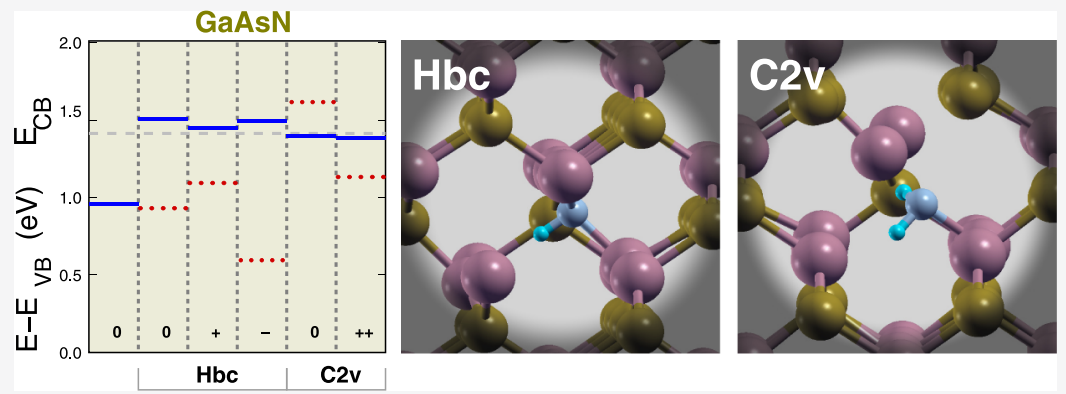

ABSTRACT: Experiments suggest that atomic $\mathrm{H}$ neutralizes the effects of $\mathrm{N}$ (i.e., it recovers the host energy gap) without inducing any band-filling effect (i.e., without behaving as a shallow donor) in the GaAsN alloy, while the vice versa is true in the InAsN one. Moreover, theoretical results on $\mathrm{H}$ in GaAsN contradict some experiments. These facts motivated the present study, where the role of $\mathrm{N}-\mathrm{H}$ complexes has been investigated by performing density functional theory-Heyd-Scuseria-Ernzerhof calculations. Present results confirm and explain the $\mathrm{H}$ properties; $\mathrm{N}$ neutralization is certain only in GaAsN, while $\mathrm{H}$ behaves as a shallow donor only in InAsN. They also show that, despite an identical geometry, single-H complexes neutralize the $\mathrm{N}$ effects in GaAsN, not in InAsN. This result is accounted for by a simple model showing that: (i) band gap recovery is directly related to a recovery of the atomic charge of the $\mathrm{Ga} / \mathrm{In}$ cations neighboring the $\mathrm{N}$ atom in a $\mathrm{N}-\mathrm{H}$ complex and (ii) a larger extent of charge recovery is found for the $\mathrm{Ga}$ cations with respect to the In ones, consistently with an electronegativity larger for Ga than for In. Remarkably, the same reason is at the ground of the different $\mathrm{H}$ behavior, deep versus shallow, in the two GaAsN and InAsN alloys.

\section{INTRODUCTION}

When introduced in a semiconducting material, thanks to their high chemical reactivity and mobility, $\mathrm{H}$ atoms diffuse in the host lattice by interacting and forming complexes with host and foreign atoms, thus strongly changing their chemical environment. This induces significant effects on the electronic and optical material properties. In particular, in III-V semiconductors, atomic $\mathrm{H}$ generally behaves as a deep, amphoteric impurity that plays the role of a donor in the presence of shallow acceptors and vice versa. ${ }^{1-3}$ Moreover, first, $\mathrm{H}$ compensates donors or acceptors, then, it diffuses and forms complexes with the dopant atoms by fully neutralizing their activity. $H$ can also neutralize the effects of an isoelectronic impurity, similar to $\mathrm{N}$-substituting anion atoms in III-V-N dilute nitride alloys, such as GaAsN. This is a particularly interesting case because small percentages of $\mathrm{N}$ induce a remarkable reduction of the host band gap. $\mathrm{H}$ atoms form $\mathrm{N}-\mathrm{H}$ complexes by strongly perturbing the $\mathrm{N}$ chemical bonds and neutralizing the $\mathrm{N}$ effects, thus inducing a gradual reopening of the band gap which culminates with a full recovery of the host band gap. ${ }^{4-6}$ In III-V-N alloys, this $\mathrm{H}$ effect can be precious to realize a fine-tuning of such a fundamental physical property. The band gap of these alloys can be changed indeed: (i) by varying the III-V alloy composition, (ii) by introducing different, small percentages of $\mathrm{N}$, and (iii) by performing hydrogenation treatments in order to realize a controlled neutralization of the $\mathrm{N}$ effects. This ability of $\mathrm{H}$ atoms to neutralize the effects of $\mathrm{N}$ has opened the way for defect engineering procedures such as, for instance, recently implemented lithographic approaches aiming to realize site-controlled single photon emitters either isolated ${ }^{7,8}$ or integrated in photonic crystal cavities. ${ }^{9,10}$ Finally, it has been shown that hydrogen incorporation in the InAsN alloy can be exploited to reach high electron concentrations and mobilities. $^{11}$

In the family of III-V-N alloys, GaAsN and InAsN play a primary role because they show very different electronic

Received: June 5, 2020

Revised: July 27, 2020

Published: August 3, 2020

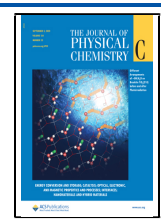


properties that offer the opportunity to be variously combined when these two ternary alloys form the more complex, quaternary InGaAsN one. The latter has received particular attention for its high potential in technological applications. In fact, InGaAsN is a light-emitting material, which has a band gap suitable for long wavelength laser diodes at $1.3 \mu \mathrm{m}$ and can be grown pseudomorphically on a GaAs substrate. ${ }^{12}$ These features and the above possibilities of a band gap tuning and high electron mobilities make a full understanding of the effects of hydrogenation on the properties of this quaternary alloy an especially important issue. This immediately turns the attention to the effects induced by hydrogen on the properties of its ternary end points, GaAsN and InAsN. An investigation of such properties is further stimulated by the noticeable differences shown by the $\mathrm{H}$ in the two compounds. In GaAsN, as mentioned above, experiments have shown that the main effect of hydrogen is to neutralize the effects of $\mathrm{N}$. On the contrary, such a $\mathrm{H}$ effect has been questioned in a recent study on hydrogenated InAsN. ${ }^{13}$ The same study has shown that the formation of $\mathrm{N}-\mathrm{H}$ complexes is accompanied by remarkable band-filling effects, thus suggesting that $\mathrm{H}$ can behave as a shallow donor in this alloy, also in agreement with the mentioned, observed increase in free electron concentration. ${ }^{11}$ Such a behavior has not been observed in GaAsN and, what is more, it seems to be ruled out by two different experimental findings. First, photoluminescence (PL) experiments show that $\mathrm{H}$ incorporation in GaAsN does not modify the lineshape of the PL spectrum (apart from the blue-shift of the emission peak related to the band gap opening), while in InAsN, it induces major variations of the PL lineshape, resulting in a long high-energy tail characteristic of a degenerate semiconductor. ${ }^{13}$ Second, the resistivity of hydrogenated GaAsN increases up to three orders of magnitude with respect to $\mathrm{H}$-free GaAsN, thus ruling out $\mathrm{H}$ as a possible donor source. ${ }^{14}$ Thus, $\mathrm{H}$ seems to induce opposite effects in the two alloys: recovery of the host energy gap together with no shallow donor behavior in GaAsN, vice versa in InAsN. Such a noticeably different behavior is rather unexpected and, therefore, interesting in and of itself. It also enhances the differences between the two alloys and this deserves to be deepened because such differences can have critical consequences when the GaAsN and InAsN alloys are combined to form the InGaAsN one.

On the side of theoretical simulations, several density functional theory (DFT) studies have investigated the structure and the properties of $\mathrm{N}-\mathrm{H}$ complexes in GaAsN. ${ }^{4,15-17}$ In detail, single-H complexes have been considered, where the $\mathrm{H}$ atom is located at a bond-centered (bc) or at an antibonding (ab) site close to an $\mathrm{N}$ atom, $\mathrm{N}-\mathrm{H}_{\mathrm{bc}}$ and $\mathrm{N}-\mathrm{H}_{\mathrm{ab}}$ complexes, respectively, see Figure 1a,d (hereafter, for the sake of conciseness such complexes may be indicated simply as $\mathrm{H}_{\mathrm{bc}}$ or $\mathrm{H}_{\mathrm{ab}}$ ). Similar complexes can be formed by $\mathrm{H}$ involving a $\mathrm{Ga}-\mathrm{As}$ bond instead of $\mathrm{a} \mathrm{Ga}-\mathrm{N}$ one $\left(\mathrm{As}-\mathrm{H}_{\mathrm{bc}}\right.$ and As $-\mathrm{H}_{\mathrm{ab}}$ complexes). Moreover, a single $\mathrm{H}$ atom may occupy (almost) tetrahedral interstitial sites in the GaAs lattice, weakly interacting with surrounding host atoms, thus forming $\mathrm{iH}$ complexes, see Figure $1 \mathrm{~b}$. Multi-H complexes have been also investigated, such as the canted $C_{2 v}$ complex, ${ }^{4,18-20}$ see Figure 1c. Previous theoretical studies have investigated the vibrational properties of single- and multi-H complexes. Comparisons of such results with accurate infrared spectroscopy measurements ${ }^{4,19,21,22}$ have supported the formation of the canted $C_{2 v}$ complex, possibly accompanied by that of single $\mathrm{N}-\mathrm{H}$ complexes. Theory has also suggested the ability of this

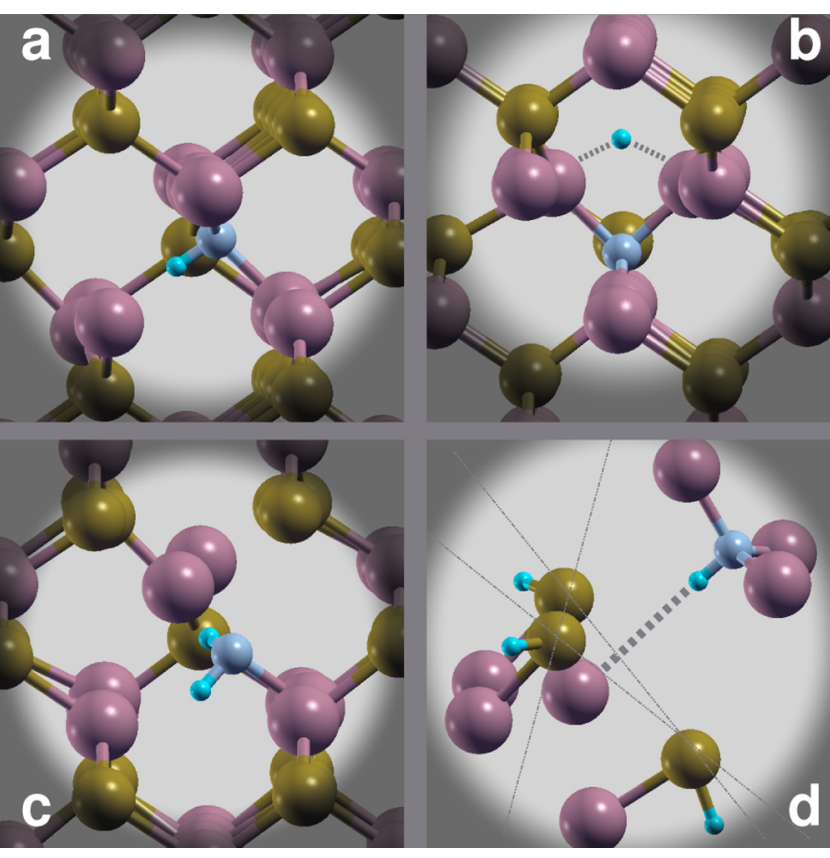

Figure 1. Main H-complexes investigated here. The GaAsN case is displayed, but the same geometries hold also for InAsN. (a) $\mathrm{N}-\mathrm{H}_{\mathrm{bc}}$; (b) $\mathrm{iH}$; (c) $\mathrm{C}_{2 v}$; (d) $\mathrm{H}_{\mathrm{bc}}-3 \mathrm{H}_{\mathrm{ab}}$ : the last figure shows $\mathrm{H}$ atoms close to $\mathrm{ab}$ sites (in the $\mathrm{ab}$ site, a $\mathrm{H}$ atom is bonded to an As one along the line of an elongated $\mathrm{Ga}-\mathrm{As}$ bond). In the same figure, dot-dashed gray lines help in identifying the 3As-plane passed through by the central $\mathrm{Ga}$ atom. Given the difficulty in visualization of all the details in perspective, in (d) only the atoms relevant to the complex have been shown. Red, yellow, and grey spheres identify Ga, As, and N atoms, respectively. Small light blue spheres identify $\mathrm{H}$ atoms.

multi-H complex to induce the neutralization of the $\mathrm{N}$ effects. Such an ability was not attributed instead to single $\mathrm{N}-\mathrm{H}$ complexes. ${ }^{16,23}$ One theoretical study investigated in detail the properties of the $\mathrm{N}-\mathrm{H}_{\mathrm{bc}}, \mathrm{N}-\mathrm{H}_{\mathrm{ab}}$, and $\mathrm{iH}$ complexes in GaAsN. ${ }^{16}$ In this study, it was proposed that $\mathrm{H}$ in the $\mathrm{N}-\mathrm{H}_{\mathrm{bc}}$ complex behaves as a shallow donor. Then, by taking into account that a $\mathrm{H}$ shallow donor behavior in GaAsN should be enhanced in a material with a smaller energy gap, such as InGaAsN, and the results achieved in the former material were used to explain an increase of n-type carriers observed by Hall measurements in $\mathrm{H}$-containing InGaAsN samples. ${ }^{24,25}$ However, as mentioned above, a $\mathrm{H}$ shallow behavior in $\mathrm{GaAsN}$ has been ruled out by experimental findings.

On the other hand, to the best of our knowledge, there are no theoretical studies of the $\mathrm{H}$ properties in InAsN. There are, therefore, some inconsistencies in the above picture, which are accompanied by an overall, crucial lack of information about the striking differences between the $\mathrm{H}$ properties in the GaAsN and InAsN alloys. Such issues have motivated the present study, which is focused on the two possible effects of $\mathrm{H}$ incorporation in the GaAsN or InAsN lattices, as we introduced above: (i) the neutralization of the effects of $\mathrm{N}$, that is, the recovery of the host energy gap and (ii) a $\mathrm{H}$ shallow donor behavior, which can induce band filling effects. In detail, the structural and electronic properties of $\mathrm{H}$ complexes in the GaAsN and InAsN alloys have been investigated here by performing DFT with the Heyd-Scuseria-Ernzerhof hybrid functional $^{26}$ (DFT-HSE) calculations in a supercell approach. DFT-HSE methods are known for being more precise in the description of band edges with respect to standard generalized 
gradient approximation (GGA) ones, and therefore, they have been chosen in order to get accurate indications on the $\mathrm{H}$ effects on the host energy gap. ${ }^{27}$ For the sake of completeness with previous results, the study has also been extended to the $\mathrm{H}$ properties in pristine GaAs and InAs.

The present results account for the significantly different properties of $\mathrm{H}$ in $\mathrm{GaAsN}$ and $\mathrm{InAsN}$, finally painting into a single framework picture consistent with the experiments. Regarding $\mathrm{H}$ shallow donor behavior, neither single- $\mathrm{H}$ nor multi-H complexes show such properties in GaAsN, in agreement with the experimental suggestions and at variance with previous theoretical results. ${ }^{16}$ In InAsN, on the contrary, both single- $\mathrm{H}$ and multi-H (i.e., $C_{2 v}$ ) complexes display a donor-like behavior, once more in agreement with the experiments. These results offer, therefore, an alternative explanation of the above mentioned increase of $n$-type carriers observed in InGaAsN ${ }^{24,25}$ which is based on the $\mathrm{H}$ shallow donor behavior in InAsN, without requiring a similar behavior in GaAsN. Regarding the energy gap recovery, we find that, at variance with previous theoretical results, ${ }^{4,16,23}$ both singleand multi-H complexes neutralize the effects of $\mathrm{N}$ in GaAsN. This is a significant result because it guarantees that, in this alloy, the process of $\mathrm{N}$ neutralization by $\mathrm{H}$ will be effective independent of the relative concentrations of $\mathrm{H}$ and $\mathrm{N}$. In InAsN, on the other hand, single $\mathrm{N}-\mathrm{H}$ complexes do not recover the energy gap. The achievement of a full passivation requires the formation of multi-H complexes, thus suggesting that $\mathrm{N}$ neutralization can occur, but it requires suitable $\mathrm{H}$ concentrations, higher than the $\mathrm{N}$ ones. Therefore, present results do not exclude such a $\mathrm{H}$ effect in InAsN alloys, in a partial disagreement with the experimental results mentioned above. ${ }^{13}$ However, it seems that further experimental investigation should be performed before definitively ruling out $\mathrm{N}$ neutralization by $\mathrm{H}$ in such alloys. In fact, the possible concomitant effects of band filling (because of donor concentration increase) and of band gap opening (because of $\mathrm{N}$ passivation) are not easy to disentangle: both induce a blueshift of the emission peak (and fully recover the energy gap). Furthermore, the PL spectra of hydrogenated InAsN are accompanied by a sizable lineshape broadening, which makes an exact determination of the band gap value hard to attain. ${ }^{13}$

Some of the present results are somewhat surprising. In fact, it is not immediately clear why single- $\mathrm{H}$ complexes fully neutralize the $\mathrm{N}$ effects in $\mathrm{GaAsN}$, but not in InAsN, despite an almost identical geometry and, therefore, a perturbation of the $\mathrm{N}$ properties expected to be quite similar. This result seems even more unclear when one considers that such a different ability to neutralize the effects of $\mathrm{N}$ disappears in the case of multi-H complexes, sharing quite similar geometries too. We show below that both results can be accounted for by a simple qualitative model, which deepens our understanding of the $\mathrm{H}$ induced $\mathrm{N}$ neutralization by showing that: (i) the energy gap recovery caused by the formation of a $\mathrm{N}-\mathrm{H}$ complex can be related to a recovery of the atomic charge of the Ga/In cations neighboring the $\mathrm{N}$ impurity. More specifically, a gradual increase of the atomic charge of these Ga (or In) atoms, induced by the complex formation, can be considered as a signal of the progressive weakening of the perturbations caused by $\mathrm{N}$ on its host environment, which culminates with the $\mathrm{N}$ neutralization; (ii) in the $\mathrm{N}-\mathrm{H}$ complexes, Ga cations tend to recover their own charge up to a larger extent with respect to In cations. This explains the different (comparable) effectiveness of a same single- $\mathrm{H}$ (multi-H) complex in neutralizing the
$\mathrm{N}$ effects on the GaAsN and InAsN energy gaps and, therefore, the overall different $\mathrm{H}$ effectiveness in producing such an effect in the two alloys; and (iii) the $\mathrm{H}$ effects can be seen from a novel perspective, where the attention moves from $\mathrm{N}$ and the electronic impurity states responsible of the host energy gap reduction to the local environment surrounding the $\mathrm{N}-\mathrm{H}$ complex, that is, to its $\mathrm{Ga} / \mathrm{In}$ neighbors and their atomic properties.

From this model, it immediately follows that the different effectiveness of the $\mathrm{Ga}$ and In cations to recover atomic charge and, therefore, of $\mathrm{H}$ to recover the host energy gap, can be related to the different cation electronegativity, larger for Ga than for In. Remarkably, even the differences concerning the $\mathrm{H}$ shallow donor behavior in the two alloys can be explained by such a different electronegativity. The different effects of $\mathrm{H}$ in the GaAsN and InAsN alloys, therefore, can be ultimately traced back to the different Ga and In chemical properties, in particular, to their different tendency to attract the electrons of a bond.

\section{THEORETICAL METHODS}

Our DFT-HSE simulations began with the location of the equilibrium parameters, such as atomic structure, lattice parameter, bulk modulus, and energy gap, of GaAs and InAs in their most stable cubic zinc-blend crystal form. Then, the same methods have been used for the investigation of the equilibrium structures and of the electronic properties of the GaAsN and InAsN alloys and of the complexes formed by atomic $\mathrm{H}$ with $\mathrm{N}$ and with the host atoms in these alloys, as well as for understanding the effects of the complex formation on the host energy gap.

In detail, we used DFT with the range separated HSE06 hybrid functional, ${ }^{26,28}$ as implemented with plane wave basis sets in the Quantum ESPRESSO ${ }^{29,30}$ suite of programs. Nuclei and core electrons have been substituted by optimized normconserving Vanderbilt's pseudopotentials. ${ }^{31}$ Explicit valence pseudo-wavefunctions were $2 \mathrm{~s}$ and $2 \mathrm{p}$ for $\mathrm{N}$; $3 \mathrm{~s}$ and $3 \mathrm{p}$ for As; $3 d, 4 s$, and $4 p$ for $\mathrm{Ga}$; and $4 d, 5 s$, and $5 p$ for In. The plane wave and density cutoffs were 80 and $320 \mathrm{Ry}$, respectively. The short-range part of the hybrid exchange functional is defined as a linear combination of a part coming from the exact HartreeFock exchange and a part coming from the GGA exchange functional in use

$$
E_{\mathrm{x}}^{\mathrm{hybr}}=\alpha E_{\mathrm{x}}^{\mathrm{Fock}}+(1-\alpha) E_{\mathrm{x}}^{\mathrm{GGA}}
$$

In the present case, the coefficient $\alpha=0.32$ has been chosen in order to best describe the Kohn-Sham (KS) band gap in InAs. Error induced in the GaAs KS band gap is around a reasonable $7 \%$. Spin-orbit couplings were not taken into account. We expect an error of a few $\mathrm{meV}$ from this choice, and we think it does not balance the further computational burden it brings into the calculations.

We anticipate that, similar to the cases of GaAs and InAs, in all of the systems investigated here, the energy gap values have been estimated by the KS hybrid functional eigenvalues, as the adequacy of this choice has been demonstrated, especially when the functionals are tuned to reproduce the experimental band gaps of the pristine materials. ${ }^{27}$ The GaAs and InAs calculations, aimed at obtaining the equilibrium properties, were carried out using the 2-atom zinc-blend unit cell, and sampling the Brillouin zone with a $8 \times 8 \times 8 k$-point Monkhorst-Pack mesh. Equilibrium lattice parameters and 
bulk moduli were fitted using a Birch-Murnaghan equation of state. Table 1 compares the present results with previous theoretical (at a comparable level of theory) and experimental results.

Table 1. Structural Data of Pristine Materials ${ }^{a}$

\begin{tabular}{|c|c|c|c|c|c|c|}
\hline & \multicolumn{3}{|c|}{ GaAs } & \multicolumn{3}{|c|}{ InAs } \\
\hline & \multicolumn{3}{|c|}{ prev. } & \multicolumn{3}{|c|}{ prev. } \\
\hline & present & theory & expt. & present & theory & expt. \\
\hline$a(\AA)$ & 5.631 & 5.686 & 5.653 & 6.042 & 6.116 & 6.058 \\
\hline$B_{0}(\mathrm{GPa})$ & 73.4 & 72.0 & 75.7 & 60.1 & 57.9 & 57.9 \\
\hline$E_{\mathrm{g}}(\mathrm{eV})$ & 1.414 & & 1.519 & 0.418 & & 0.417 \\
\hline
\end{tabular}

${ }^{a}$ Comparison with results from refs 32,33 and references therein.

Lattice parameters, band gaps, and bulk moduli deviate from experimental values by at most $0.4,7$, and $4 \%$, respectively.

The properties of $\mathrm{H}$ complexes in pristine materials and in GaAsN and InAsN alloys have been investigated by using 64atom and 128-atom supercells. In the case of 64-atom simple cubic supercells, given the heavy computational demand of hybrid functional simulations, geometry optimizations were performed sampling the Brillouin zone at the $\Gamma$ point. Total energies, electronic eigenvalues, and density of states as well as their projection on atomic states were obtained by single-point calculations on a $2 \times 2 \times 2 k$-point mesh including the $\Gamma$ point. When using 128-atom supercells, the same computational constraints led us to limit the Monkhorst-Pack sampling to the $\Gamma$-point only.

Given the crucial role of the energy gap value in the present study, we have checked the convergence of this quantity with respect to the supercell size. 64-atom supercells assure a satisfactory convergence in the case of GaAs and GaAsN. For InAs and InAsN, instead, we needed to resort to 128-atom supercells. In detail, in pristine InAs the DFT-HSE 128-atom supercell energy gap is $\approx 0.38 \mathrm{eV}$ (against an experimental value of $0.418 \mathrm{eV}$ ). In InAsN, the energy gap is $0.216 \mathrm{eV}$, which is in a quite good agreement with the experiment, 0.265 $\mathrm{eV},{ }^{34}$ when it is taken into account that the $\mathrm{N}$ concentration is around $1.5 \%$ in such a supercell. The DFT-HSE GaAsN energy gaps are 0.876 and $0.96 \mathrm{eV}$ in 64-atom ( $\mathrm{N}$ concentration around 3\%) and 128-atom supercells, respectively, which are in a satisfactory agreement with the experimental values of $1.056^{35}$ and $1.181 \mathrm{eV},{ }^{35}$ estimated at the corresponding 3 and $1.5 \% \mathrm{~N}$ concentrations, respectively. The worse agreement achieved in the case of GaAsN is a consequence of the tuning of the parameter $\alpha$, see eq 1 , to improve the accuracy of the estimate for the more problematic (quite small) InAsN energy gap.

In the present study, a further fundamental quantity is the formation energy of a $\mathrm{H}$ complex, $H_{\mathrm{f}}$. For instance, in the case of a $\mathrm{N}-\mathrm{H}$ complex containing $n \mathrm{H}$ atoms in the charge state $q$ (see e.g., ref 27 and references therein)

$$
\begin{aligned}
H_{\mathrm{f}}[\mathrm{N}-n \mathrm{H}](q)= & E[\mathrm{~N}-n \mathrm{H}](q)-E[\mathrm{~N}]-n \mu_{\mathrm{H}} \\
& +q\left(\epsilon_{\mathrm{F}}+\epsilon_{\mathrm{VB}}\right)
\end{aligned}
$$

where $E[\mathrm{~N}-n \mathrm{H}](q)$ and $E[\mathrm{~N}]$ are the total energy of the supercell containing the complex in a charge state $q$, and the nitride alloy without $\mathrm{H}$, respectively. The third term keeps into account the addition to the system of $n$ hydrogen atoms $(n>$ $0)$, considered at a chemical potential $\mu_{\mathrm{H}}$. Here, $\mu_{\mathrm{H}}$ corresponds to half of the total energy of a $\mathrm{H}_{2}$ molecule in vacuum. Electrons are exchanged with a reservoir, whose chemical potential is the Fermi energy $\epsilon_{\mathrm{F}}$, referred to the valence band maximum, $\epsilon_{\mathrm{VB}}$.

Formation energies as defined in eq 2 may be used to determine the charge states of a complex in the system as a function of the Fermi energy of the electron reservoir. Equating formation energies of the $\mathrm{N}-n \mathrm{H}$ complex in the charge states $q$ and $q^{\prime}$ gives the transition level

$$
\varepsilon\left(q / q^{\prime}\right)=\frac{E[\mathrm{~N}-n \mathrm{H}]\left(q^{\prime}\right)-E[\mathrm{~N}-n \mathrm{H}](q)}{q-q^{\prime}}-\epsilon_{\mathrm{VB}}
$$

that is the Fermi energy value at which the complex passes from charge $q$ to charge $q^{\prime}$. By following the Di Valentin's approach $^{36,37}$ and exploiting the Janak's theorem, it is possible to reformulate the numerator in the right side of eq 3 in terms of the eigenvalues of the highest occupied state $+1, \epsilon_{h+1}$

$$
\begin{array}{r}
E[\mathrm{~N}-n \mathrm{H}]\left(q^{\prime}\right)-E[\mathrm{~N}-n \mathrm{H}](q) \\
=\frac{\epsilon_{h+1}\left(N_{\mathrm{e}}\right)+\epsilon_{h+1}\left(N_{\mathrm{e}}+1\right)}{2}
\end{array}
$$

where the number of electrons, $N_{\mathrm{e}}$, has been explicitly shown for clarity.

We have used Di Valentin's approach for InAs and InAsN because $\Gamma$ point eigenvalues have significant effects on the transition energy values, and effects likely related to the small energy gaps and the rather sharp shape of the conduction band minimum (CBM) that characterize both compounds. This would require very dense Monkhorst-Pack meshes sampling the Brillouin zone or, alternatively, very large supercells and, therefore, computer resources hard to be affordable for accurate DFT-HSE simulations. Di Valentin's approach permits instead of exploiting the accuracy of the DFT-HSE KS eigenvalues at the $\Gamma$ point, for estimating the transition energy values. In this way, our tests have shown that satisfactorily converged transition energy values can be achieved by using 64 -atom and 128 -atom supercells in the simulations regarding GaAs- and InAs-based compounds, respectively. The same holds for equilibrium geometries and total energies. Thus, when not explicitly stated, in the following sections, the results for the GaAsN and InAsN alloys have been achieved by using these two different supercell sizes, respectively.

For the calculation of Bader atomic charges, ${ }^{38,39}$ we postprocessed the outcomes of $\mathrm{VASP}^{40-45}$ simulationsperformed on the relevant geometries obtained via Quantum ESPRESSO (as outlined above) - by means of the utility developed by Henkelman's group. ${ }^{46}$ VASP calculations have been performed with the same HSE06 functional, PAW pseudopotentials, $400.0 \mathrm{eV}$ cutoff for plane waves and a $2 \times 2$ $\times 2 k$-point Monkhorst-Pack mesh.

\section{DISCUSSION AND RESULTS}

H Effects on the GaAsN Properties. Recovery of the Host Energy Gap. It is known that substitutional $\mathrm{N}$ in GaAs lowers the energy gap. ${ }^{47}$ With the purpose of considering the role of different single- and multi-H complexes on the neutralization of such a N-effect in GaAsN and the ensuing recovery of the host band-gap, in the upper panel of Figure 2 we show some relevant HSE KS electronic eigenvalues at the $\Gamma$ point, by assuming the maximum of the valence band (VBM) 

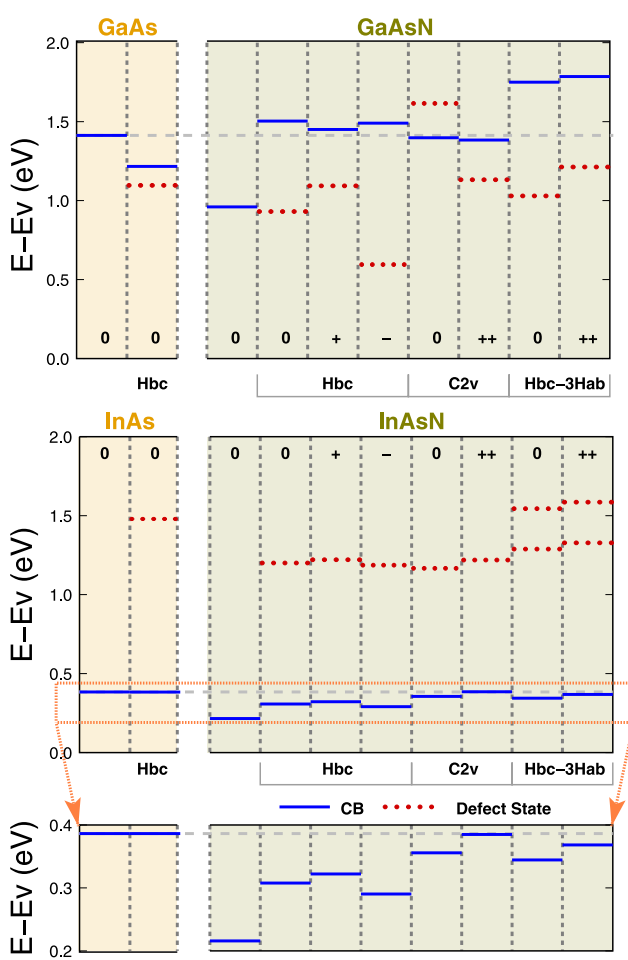

Figure 2. Diagram of the CBM and defect levels induced by different $\mathrm{H}$ complexes, with respect to the VBM. Upper panel: GaAs and GaAsN. Lower panel: InAs and InAsN. Both GaAsN and InAsN results have been achieved by using 128 -atom supercells. The charge state of each complex is also indicated in each panel.

as a common reference point. In particular, in the figure, we have defect energy levels in the gap (if any) and the CBM for each $\mathrm{H}$ complex studied in GaAsN, together with results for pristine GaAs. The GaAsN results in the figure have been achieved by using 128 -atom supercells.

A remark is due on the last two columns of the diagrams in Figure 2. Here, we show results relative to a 4-H complex, $\mathrm{H}_{\mathrm{bc}}-3 \mathrm{H}_{\mathrm{ab}}$, whose structure is described in Figure $1 \mathrm{~d}$. In the quest for a complex that might show a shallow donor behavior, we considered the $\mathrm{H}_{\mathrm{bc}}-3 \mathrm{H}_{\mathrm{ab}}$ one because we got inspired by the results we previously reported in hydrogenated InGaN alloys $^{48}$ and InN. ${ }^{49}$ Similar to what occurs in InGaN alloys, in GaAsN, the $\mathrm{H}_{\mathrm{bc}}-3 \mathrm{H}_{\mathrm{ab}}$ complex forms in a $3 \mathrm{As}-(\mathrm{Ga})-\mathrm{N}$ tetrahedron; three $\mathrm{H}$ atoms form three As $-\mathrm{H}_{\mathrm{ab}}$ bonds with the As atoms neighboring the central $\mathrm{Ga}$ atom, thus pulling these atoms away from the $\mathrm{Ga}$ one and favoring, at the same time, the insertion of an $\mathrm{H}_{\mathrm{bc}}$ atom into the $\mathrm{Ga}-\mathrm{N}$ bond. The existence of a complex with this geometry was supported by $\mathrm{X}$ ray absorption near edge structure experiments ${ }^{48}$ and by the study on hydrogenated $\operatorname{InN} .^{49}$ A peculiarity of the $\mathrm{H}_{\mathrm{bc}}-3 \mathrm{H}_{\mathrm{ab}}$ complex in InGaN and $\mathrm{InN}$ is that the two pairs of electrons introduced by the four $\mathrm{H}$ atoms in the complex occupy a defect electronic state in the host energy gap and the CBM, respectively. Given such a shallow behavior in InGaN alloys, this complex is, therefore, a potential candidate to show a similar feature in GaAsN and InAsN alloys. As a first remarkable difference, in $\mathrm{InGaN}$ and $\mathrm{InN}$, the involved $\mathrm{Ga}$ or In atom maintains a central position, while in the presently simulated systems, GaAsN and InAsN, the central Ga (In) atom moves to the other side of the plane formed by its three As neighbors, instead of remaining at the center of the tetrahedron, see Figure 1d.
In order to identify the nature of a given $\mathrm{KS}$ electronic state, we have investigated its composition in terms of the relative contributions of $\mathrm{Ga}$, As, and $\mathrm{N}$ atomic, electronic states. As it is well known, in III-V compounds, the VBM and the CBM are mainly contributed by anionic and cationic electronic states, respectively. In GaAsN, the CBM is mainly contributed by the $\mathrm{s}$ states of $\mathrm{N}$ and of its four Ga neighbors, as well as by states of the other Ga bulk atoms, that is, Ga atoms not bonded to $\mathrm{N}$. On the other hand, as an example, in the neutral $\mathrm{N}-\mathrm{H}_{\mathrm{bc}}(0)$ complex (with an on-line $\mathrm{Ga}-\mathrm{H}-\mathrm{N}$ geometry, see Figure 1a), the first KS level above the VBM is significantly more localized on the p orbitals of the $\mathrm{Ga}$ atom and the $\mathrm{s}$ orbital of the $\mathrm{N}$ atom involved in the complex. This is, therefore, a defect level. The next level, higher in energy, is mainly contributed by the same $\mathrm{p}$ orbitals of the $\mathrm{Ga}$ in the complex and by s orbitals of other Ga bulk atoms, whereas there is no contribution from the $\mathrm{N}$ atom. This state corresponds, therefore, to the recovered GaAs CBM. Its value (1.50 eV against a GaAs energy gap of $1.41 \mathrm{eV}$ ) and composition testify the neutralization of the $\mathrm{N}$ effects on the GaAs energy gap induced by the $\mathrm{N}-\mathrm{H}_{\mathrm{bc}}(0)$ complex. By performing a similar analysis on all of the relevant $\mathrm{KS}$ levels, for all of the investigated $\mathrm{H}$-complexes, the present results show that all of the single- and multi-H complexes, in the different charge states, recover the GaAs energy gap. In the case of the $\mathrm{N}-\mathrm{H}_{\mathrm{bc}}$ complexes, these results differ from previous ones, which attributed the ability to recover the host energy gap only to the multi-H complexes, ${ }^{3,23}$ presumably because of the GGA functional used there. Present results achieved for the $\mathrm{N}-\mathrm{H}_{\mathrm{bc}}$ complex are significant, when considering that also the ability of multi-H complexes, such as the $C_{2 v}$, to neutralize the $\mathrm{N}$ effects is confirmed. ${ }^{3,4,23}$ All together, these results assure indeed that the energy gap recovery occurs independent of the relative $\mathrm{N}$ and $\mathrm{H}$ concentration, being induced by single- $\mathrm{H}$ complexes when the $\mathrm{H}$ concentration is lower than the $\mathrm{N}$ one, by multi- $\mathrm{H}$ complexes when the $\mathrm{N}$ concentration is overcome by $\mathrm{H}$.

Finally, the $\mathrm{H}_{\mathrm{bc}}-3 \mathrm{H}_{\mathrm{ab}}$ complex induces a defect level in the energy gap, which accommodates two electrons. The further two electrons introduced by the four $\mathrm{H}$ atoms are hosted by the CBM. This complex seems to induce an overshooting of the energy gap.

$\mathrm{N}-\mathrm{H}$ Complex Formation and $\mathrm{H}$ Shallow Donor Behavior. The existence of the above complexes in hydrogenated GaAsN has been investigated in two ways. First, we have estimated their formation energies as a function of the Fermi level position. As an example, let us consider the widely investigated case of single $\mathrm{H}$ complexes in GaAs. ${ }^{1-3}$ The relative formation energies are shown in Figure 3a, following eq 2. As explained in eq 3 , the crossing point between two formation energy lines gives the Fermi level position, where a complex changes its charge state. In agreement with previous findings, ${ }^{1-3}$ the crossing of the $\mathrm{H}_{\mathrm{bc}}(+)$ and $\mathrm{iH}(-)$ lines occurs below the $\mathrm{H}_{\mathrm{bc}}(0)$ line and within the GaAs energy gap. The corresponding $\varepsilon(+/-)$ is at about $0.9 \mathrm{eV}$ above the VBM. These results indicate a negative $U$ behavior of $\mathrm{H}$, already proposed in several semiconductors: ${ }^{3}$ a single $\mathrm{H}$ atom is never stable in its neutral charge state, it gets only a positive or a negative state. More specifically, as reported in previous papers, ${ }^{1-4} \mathrm{H}$ behaves as a donor for low Fermi energy values, that is, in the presence of acceptors. In this case, $\mathrm{H}$ at the bc $\mathrm{Ga}-\mathrm{As}$ site has a positive charge and compensates the acceptors. It also diffuses in the GaAs crystal lattice and forms acceptor- $\mathrm{H}$ complexes by neutralizing the acceptor 

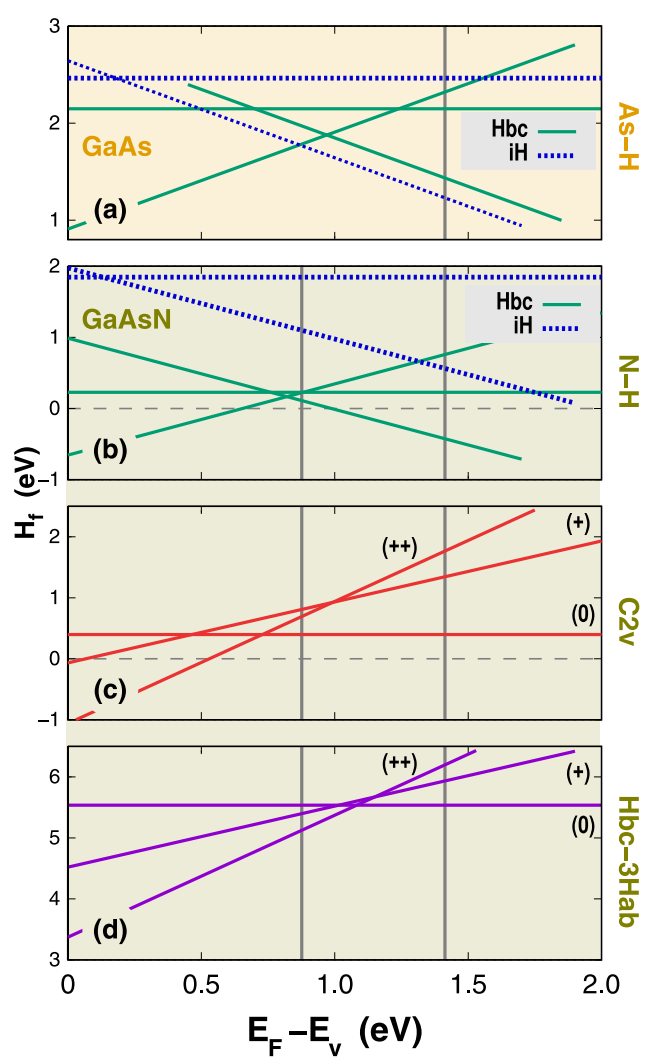

Figure 3. Formation energies, $H_{\mathrm{f}}$ with respect to Fermi energies, $E_{\mathrm{F}}$, referred to the valence band maximum, $E_{\mathrm{V}}$. Light yellow background indicates diagram for $\mathrm{H}$-complexes in GaAs. Light green background indicates diagrams for $\mathrm{H}$-complexes in GaAsN. Vertical gray lines indicate the CBM; $1.413 \mathrm{eV}$ for GaAs, $0.876 \mathrm{eV}$ for GaAsN.

activity. Similarly, for high Fermi level values, $\mathrm{H}$ gets a negative charge when located in interstitial (almost) tetrahedral sites, $\mathrm{iH}(-)$, compensates donors, diffuses, and binds to them by neutralizing their activity. ${ }^{4}$ In the absence of donors or acceptors, the $\mathrm{H}_{\mathrm{bc}}(+)$ and $\mathrm{iH}(-)$ species coexist. Present results, obtained with DFT-HSE06 simulations and exploiting Di Valentin's approach, see eq 3, fully reproduce such previous findings.

Formation energy graphs, as a function of the Fermi level positions, can give also indications on a possible shallow donor behavior of a $\mathrm{H}$ complex, that is the second $\mathrm{H}$-complex property we are interested in. As an example, let us consider the case of single $\mathrm{H}$ complexes in GaAsN, in Figure 3b. Here, a $\mathrm{H}$ bonded to an $\mathrm{N}$ atom in the $\mathrm{N}-\mathrm{H}_{\mathrm{bc}}$ complex is considered in the $(+),(0)$, and $(-)$ charge states, together with $\mathrm{iH}$ in (0) and $(-)$ charge states. When $\mathrm{H}$ behaves as an acceptor, the $\mathrm{N}-\mathrm{H}_{\mathrm{bc}}(-)$ complex turns out to be favored with respect to the $\mathrm{iH}(-)$, in contrast to pristine GaAs, where the $\mathrm{H}_{\mathrm{bc}}(-)$ complex is energetically penalized with respect to the $\mathrm{iH}(-)$ in the whole $E_{\mathrm{F}}$ range: compare Figure $3 \mathrm{a}, \mathrm{b}$.

Present results show that the $\mathrm{H}_{\mathrm{bc}}(+) / \mathrm{H}_{\mathrm{bc}}(-) \varepsilon(+/-)$ value is smaller than the GaAsN energy gap, that is, $\mathrm{H}$ behaves as a negative- $U$ defect. On the contrary, if $\mathrm{H}$ was a shallow donor, the $\mathrm{H}_{\mathrm{bc}}(+)$ complex would be stable in the whole range of allowed $E_{\mathrm{F}}$ values, that is, it would be characterized by an $\varepsilon(+/-)$ value larger than the GaAsN energy gap.

A shallow donor behavior of $\mathrm{H}$ was predicted in a mentioned, previous work, ${ }^{16}$ where an $\varepsilon(+/-)$ value about $0.03 \mathrm{eV}$ larger than the GaAsN energy gap was estimated. Present results give, instead, a value $0.02 \mathrm{eV}$ smaller than the GaAsN gap. On the ground of these unmatching results, the $\mathrm{H}$ behavior would remain rather uncertain. However, at variance with the results of previous studies, ${ }^{16,23}$ the present results indicate that the $\mathrm{H}_{\mathrm{bc}}(+)$ complex in $\mathrm{GaAsN}$ restores the GaAs energy gap. This implies that the $\varepsilon(+/-)$ value in Figure $3 \mathrm{~b}$ has to be compared with the GaAs energy gap instead of the $\mathrm{GaAsN}$ one. From the present results, single-H complexes do not behave, therefore, as shallow donors in GaAsN.

We have seen in eq 2 that formation energies estimate the energy balance of the formation process of a $\mathrm{H}$ complex in a given charge state with respect to a common state of reference corresponding to the host material and a $\mathrm{H}$ atom in the gas phase. However, once introduced in a host lattice, $\mathrm{H}$ atoms interact with the host atoms forming mobile complexes such as, for example, the $\mathrm{H}_{\mathrm{bc}}(+)-$ As ones, and, in this form, they migrate in the crystal lattice ${ }^{50}$ and interact with $\mathrm{N}$ atoms. Thus, $\mathrm{N}-\mathrm{H}$ complexes can be also considered as the products of reactions involving $\mathrm{N}$ atoms and the $\mathrm{H}$-related reacting species coming from the $\mathrm{H}-$ (host atom) interactions. For instance, Figure $3 \mathrm{a}$ indicates that, in a Fermi level range limited by the GaAsN energy gap $(0.87 \mathrm{eV}), \mathrm{H}$ atoms interacting with the host $\mathrm{Ga}$ and As atoms initially form only the As- $\mathrm{H}_{\mathrm{bc}}(+)$ complex. In this form, $\mathrm{H}^{+}$ions diffused in the lattice are

Table 2. Schematic Description of Reactions Leading to the Formation of N-H Complexes in GaAsN and InAsN Systems ${ }^{a}$

\begin{tabular}{|c|c|c|c|c|}
\hline & reactants & & products & $\Delta E(\mathrm{eV})$ \\
\hline \multirow[t]{6}{*}{ GaAs } & $(\mathrm{GaAs}) \mathrm{N}+\mathrm{As}-\mathrm{H}_{\mathrm{bc}}^{+}$ & $\rightarrow$ & $\mathrm{GaAs}+\mathrm{N}-\mathrm{H}_{\mathrm{bc}}^{+}$ & -1.52 \\
\hline & $(\mathrm{GaAs}) \mathrm{N}+(\mathrm{GaAs}) \mathrm{iH}^{-}$ & & $\mathrm{N}-\mathrm{H}_{\mathrm{bc}}{ }^{+}+\mathrm{GaAs}$ & -1.09 \\
\hline & $(\mathrm{GaAs}) \mathrm{iH}^{-}+\mathrm{N}-\mathrm{H}_{\mathrm{bc}}^{+}$ & & $C_{2 v}^{0}+\mathrm{GaAs}$ & -1.28 \\
\hline & $\mathrm{N}-\mathrm{H}_{\mathrm{bc}}^{+}+\mathrm{As}-\mathrm{H}_{\mathrm{bc}}^{+}$ & & $\mathrm{C}_{2 v}^{++}+\mathrm{GaAs}$ & -1.32 \\
\hline & $\mathrm{As}-\mathrm{H}_{\mathrm{bc}}^{+}+2(\mathrm{GaAs}) \mathrm{iH}^{-}+\mathrm{N}-\mathrm{H}_{\mathrm{bc}}^{+}$ & & $\mathrm{H}_{\mathrm{bc}}-3 \mathrm{H}_{\mathrm{ab}}^{0}+3 \mathrm{GaAs}$ & +0.66 \\
\hline & $2 \mathrm{As}-\mathrm{H}_{\mathrm{bc}}{ }^{+}+(\mathrm{GaAs}) \mathrm{iH}^{-}+\mathrm{N}-\mathrm{H}_{\mathrm{bc}}{ }^{+}$ & & $\mathrm{H}_{\mathrm{bc}}-3 \mathrm{H}_{\mathrm{ab}}{ }^{++}+3 \mathrm{GaAs}$ & -0.22 \\
\hline \multirow[t]{6}{*}{ InAs } & $($ InAs $) \mathrm{N}+\mathrm{As}-\mathrm{H}_{\mathrm{bc}}^{+}$ & $\rightarrow$ & InAs $+\mathrm{N}-\mathrm{H}_{\mathrm{bc}}^{+}$ & -1.59 \\
\hline & $($ InAs $) \mathrm{N}+(\operatorname{InAs}) \mathrm{iH}^{-}$ & & $\mathrm{N}-\mathrm{H}_{\mathrm{bc}}{ }^{-}+\mathrm{InAs}$ & -1.26 \\
\hline & $(\mathrm{InAs}) \mathrm{iH}^{-}+\mathrm{N}-\mathrm{H}_{\mathrm{bc}}^{+}$ & & $\mathrm{C}_{2 v}^{++}+\mathrm{InAs}$ & -1.04 \\
\hline & $\mathrm{N}-\mathrm{H}_{\mathrm{bc}}^{+}+\mathrm{As}-\mathrm{H}_{\mathrm{bc}}^{+}$ & & $\mathrm{C}_{2 v}^{++}+\mathrm{InAs}$ & -1.43 \\
\hline & $\mathrm{As}-\mathrm{H}_{\mathrm{bc}}^{+}+2(\mathrm{InAs}) \mathrm{iH}^{-}+\mathrm{N}-\mathrm{H}_{\mathrm{bc}}^{+}$ & & $\mathrm{H}_{\mathrm{bc}}-3 \mathrm{H}_{\mathrm{ab}}^{0}+3 \operatorname{InAs}$ & -0.18 \\
\hline & $2 \mathrm{As}-\mathrm{H}_{\mathrm{bc}}^{+}+(\mathrm{InAs}) \mathrm{iH}^{-}+\mathrm{N}-\mathrm{H}_{\mathrm{bc}}^{+}$ & & $\mathrm{H}_{\mathrm{bc}}-3 \mathrm{H}_{\mathrm{ab}}^{++}+3 \mathrm{InAs}$ & -0.72 \\
\hline
\end{tabular}

${ }^{a}$ Note that $\Delta E$ values come from differences between total energy values of simulation supercells. Thus, for example, in the $(\mathrm{GaAs}) \mathrm{N}+\mathrm{As}-\mathrm{H}_{\mathrm{bc}}(+)$ $\rightarrow \mathrm{GaAs}+\mathrm{N}-\mathrm{H}_{\mathrm{bc}}(+)$ reaction, the two reactants involve two 64-atom supercells like the two products. Stoichiometry is balanced between reactants and products. 
attracted by a $\mathrm{N}$ negative charge ( $\mathrm{N}$ acquires a partial negative charge because it is more electronegative than an As atom) and give rise to an exothermic reaction $(\mathrm{GaAs}) \mathrm{N}+\mathrm{As}-\mathrm{H}_{\mathrm{bc}}(+) \rightarrow$ $\mathrm{N}-\mathrm{H}_{\mathrm{bc}}(+)+\mathrm{GaAs}$, see Table 2. From this table, the relative $\Delta E$ value, that is, the difference in energy between products and reacting species of this reaction, is indeed equal to -1.52 $\mathrm{eV}$ (negative values indicate exothermic reactions). The $\mathrm{H}$ atom in the $\mathrm{N}-\mathrm{H}_{\mathrm{bc}}(+)$ complex neutralizes the $\mathrm{N}$ effects by restoring the GaAs energy gap, thus implying that when a suitable concentration of such complexes is reached, further $\mathrm{H}$ introduced in the GaAs lattice behaves as a negative- $U$ defect by forming $\mathrm{As}-\mathrm{H}_{\mathrm{bc}}(+)$ and $\mathrm{iH}(-)$ complexes (see Figure 3a). Both complexes can diffuse in the GaAs lattice and can be considered, together with $\mathrm{N}$ atoms and $\mathrm{N}-\mathrm{H}_{\mathrm{bc}}(+)$ complexes, as reactants in the formation of single- and multi- $\mathrm{H}$ complexes.

In this way, it is possible to discuss the formation of $C_{2 v}$ complexes in terms of both formation energies, $H_{f}$, and reaction energies, $\Delta E$. Once a large number of $\mathrm{N}-\mathrm{H}_{\mathrm{bc}}(+)$ complexes is formed, a iH( $(-)$ ion may react with a $\mathrm{N}-\mathrm{H}_{\mathrm{bc}}(+)$ complex to form the $C_{2 v}(0)$ one. This occurs with an exothermic reaction, as indicated in Table 2. Moreover, the reaction involving $\mathrm{N}-\mathrm{H}_{\mathrm{bc}}(+)$ and $\mathrm{As}-\mathrm{H}_{\mathrm{bc}}(+)$ species to form a $C_{2 v}(+2)$ complex is exothermic, see Table 2. However, the $C_{2 v}$ formation energies in Figure $3 c$ show that the $\varepsilon(+2 / 0)$ is close to the GaAs mid-gap (the GaAs energy gap is restored by the formation of $\mathrm{N}-\mathrm{H}_{\mathrm{bc}}$ or $C_{2 v}$ complexes), that is, the value of the Fermi level in undoped materials. For this Fermi level, the $C_{2 v}(+2)$ may change its charge state to the neutral one. We expect, therefore, that the $C_{2 v}(0)$ and $C_{2 v}(+2)$ complexes coexist. The same figure shows that a shallow donor behavior cannot be ascribed to the $C_{2 v}$ complex either.

Finally, the $\mathrm{H}_{\mathrm{bc}}-3 \mathrm{H}_{\mathrm{ab}}$ multi-H complex does not play a significant role in GaAsN. It is not favored in the neutral charge state (the corresponding $\Delta E$ has a positive value) and scarcely favored in the +2 one, see Table 2 . Moreover, the corresponding formation energies, see Figure 3d, show that it cannot behave as a shallow donor.

Results achieved for other $\mathrm{N}-\mathrm{H}$ complexes in GaAsN (and InAsN) have not been reported here: single- $\mathrm{H}$ complexes, such as the $\mathrm{N}-\mathrm{H}_{\mathrm{ab}}$ ones, and multi- $\mathrm{H}$ complexes, such as the $\mathrm{H}_{2}^{*}$ (see ref 17), have higher total and formation energy values.

To summarize, in $\mathrm{GaAsN}$, all of the investigated $\mathrm{N}-\mathrm{H}$ complexes restore the GaAs energy gap, while none of them can account for a band-filling effect. This is in agreement with the experimental results. ${ }^{51}$

$\mathrm{H}$ Effects on the InAsN Properties. Recovery of the Host Energy Gap. The KS electronic eigenvalues calculated for different $\mathrm{H}$ complexes in InAsN are shown in the lower panel of Figure 2. $\mathrm{N}$ has dramatic effects on the InAs energy gap, as shown by a gap value of $0.216 \mathrm{eV}$ to be compared with the value of $0.383 \mathrm{eV}$ calculated for the pristine material.

The results in the figure also show that, as opposed to GaAsN, defect levels induced by $\mathrm{N}-\mathrm{H}$ complexes are located above the CBM rather than in the InAsN energy gap (compare with the upper panel of the figure). This implies that one or two electrons occupy the CBM in the case of neutral complexes. A second, significant difference with respect to the GaAsN results in Figure 2 is that single- $\mathrm{H}$ complexes do not fully neutralize the effects of $\mathrm{N}$ by inducing only a partial reopening of the energy gap (see the zoom in the lower panel). This different ability of the $\mathrm{N}-\mathrm{H}_{\mathrm{bc}}(0)$ and $\mathrm{N}-\mathrm{H}_{\mathrm{bc}}(+)$ complexes to recover the host energy gap in the two alloys has raised our attention because, as mentioned above, these complexes have exactly the same on line geometry in the two materials and are expected to perturb the $\mathrm{N}$ properties in a quite similar way. This result is even more surprising if one takes into account that multi-H complexes-which also share a same geometry-neutralize $\mathrm{N}$ effects in both alloys. Later in this section (see below), we will introduce a new, simple model that can answer to such issues.

$\mathrm{N}-\mathrm{H}$ Complex Formation and $\mathrm{H}$ Shallow Donor Behavior. Before starting with the investigation of $\mathrm{N}-\mathrm{H}$ complex formation energies in InAsN, we have to consider the behavior of single $\mathrm{H}$ atoms in InAs. The formation energies of As $-\mathrm{H}_{\mathrm{bc}}$ in the $(+, 0,-)$ charge states and $\mathrm{iH}(-)$ complexes in this material are shown in Figure 4a. Analogous to the results

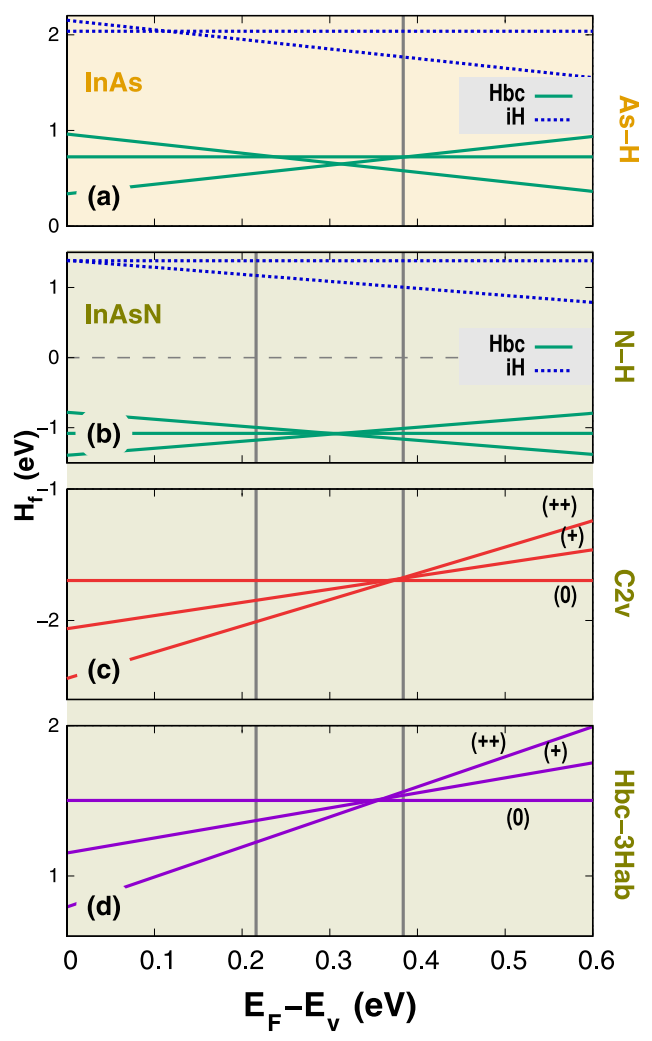

Figure 4. Formation energies, $H_{\mathrm{f}}$ with respect to Fermi energies, $E_{\mathrm{F}}$, referred to the valence band maximum, $E_{\mathrm{V}}$. Light yellow background indicates diagram for H-complexes in InAs. Light green background indicates diagrams for $\mathrm{H}$-complexes in InAsN. Vertical gray lines indicate the CBM; $0.383 \mathrm{eV}$ for InAs, $0.216 \mathrm{eV}$ for InAsN.

achieved for $\mathrm{H}$ in GaAs; in InAs, $\mathrm{H}$ behaves as a negative- $U$ defect, in agreement with previous theoretical findings. ${ }^{3}$ However, at variance with GaAs and in agreement with $\mathrm{GaAsN}$, the $\mathrm{H}_{\mathrm{bc}}(-)$ complex is lower in energy than the $\mathrm{iH}(-)$ one, and the $\varepsilon(+/-)$ value corresponds to the crossing of the $\mathrm{H}_{\mathrm{bc}}(+)$ and $\mathrm{H}_{\mathrm{bc}}(-)$ formation energy lines.

In InAsN, the considered single-H complexes, that is, the $\mathrm{N}-\mathrm{H}_{\mathrm{bc}}(0 /+/-)$, increase the energy gap up to the value of about $0.31 \mathrm{eV}$, that is, without reaching a total recovery up to a InAs gap of $0.383 \mathrm{eV}$. Their formation reactions are all exothermic, see Table 2 . The corresponding formation energies, see Figure $4 b$, indicate that the $\mathrm{N}-\mathrm{H}_{\mathrm{bc}}(+)$ complex is the dominant one for Fermi level values up to about $0.31 \mathrm{eV}$. That is, such a complex starts to form when the InAsN energy gap is $0.216 \mathrm{eV}$; then, it partially neutralizes the $\mathrm{N}$ effects by raising the energy gap up to the value of $0.31 \mathrm{eV}$. Now, because 
Table 3. Bader Atomic Charges of $\mathrm{Ga}$ and in Cations (in $e$ ) in Different $\mathrm{N}-\mathrm{H}$ Complexes ${ }^{a}$

\begin{tabular}{|c|c|c|c|c|c|c|c|c|}
\hline \multirow[t]{2}{*}{$\mathrm{X}=\mathrm{Ga}, \mathrm{In}$} & GaAsN & InAsN & GaAsN & InAsN & GaAsN & InAsN & GaAsN & InAsN \\
\hline & \multicolumn{2}{|c|}{$\mathrm{H}_{\mathrm{bc}}^{0}$} & \multicolumn{2}{|c|}{$\mathrm{H}_{\mathrm{bc}}^{+}$} & \multicolumn{2}{|c|}{$C_{2 v}^{0}$} & \multicolumn{2}{|c|}{$C_{2 v}^{++}$} \\
\hline X-bulk & 12.22 & 12.17 & 12.22 & 12.17 & 12.21 & 12.18 & 12.19 & 12.14 \\
\hline $\mathrm{X}-\mathrm{N}$ & 12.01 & 11.99 & 12.02 & 11.99 & 12.01 & 12.01 & 12.00 & 11.98 \\
\hline $\mathrm{X}-\mathrm{H}$ & 12.39 & 12.27 & 12.35 & 12.26 & 12.43 & 12.30 & 12.25 & 12.20 \\
\hline $\mathrm{X}-\mathrm{H}_{2}$ & & & & & 12.49 & 12.36 & 12.27 & 12.21 \\
\hline $\bar{X}$ & 12.10 & 12.06 & 12.09 & 12.06 & 12.23 & 12.17 & 12.13 & 12.09 \\
\hline$R$ & $45 \%$ & $35 \%$ & $43 \%$ & $34 \%$ & $109 \%$ & $94 \%$ & $68 \%$ & $64 \%$ \\
\hline $\mathrm{N}$ & 6.52 & 6.52 & 6.53 & 6.53 & 6.67 & 6.60 & 6.57 & 6.62 \\
\hline
\end{tabular}

${ }^{a} \mathrm{X}$-bulk indicates a "bulk" cation (a cation bonded with an As atom), while $\mathrm{X}-\mathrm{N}$ and $\mathrm{X}-\mathrm{H}$ label cations bonded with $\mathrm{N}$ and $\mathrm{H}$ in the complex, respectively. $\overline{\mathrm{X}}$ means atomic charge value (see the text), $R$ is the ratio between atomic charges (see the text), and $\mathrm{N}$ is nitrogen atomic charge in the complex. In GaAsN and InAsN without $\mathrm{H}$, the $\mathrm{N}$ atomic charge takes values of $6.50 e$ and $6.47 e$, respectively, whereas the four Ga or In atoms bonded to $\mathrm{N}$ have atomic charge values of $12.00 e$ and $11.98 e$, respectively.

this complex maintains its positive charge state in the whole range of the Fermi energy values $(0.0-0.31 \mathrm{eV})$, it means that $\mathrm{H}$ behaves as a shallow donor. Thus, it can account for a bandfilling effect when the $\mathrm{H}$ concentration is lower than or equal to that of $\mathrm{N}$ atoms. For $\mathrm{H}$ concentrations higher than the $\mathrm{N}$ ones, multi-H complexes can form. The $\Delta E$ values for $C_{2 v}(0)$ and $C_{2 v}(+2)$ complexes indicate that their formation reactions are exothermic, see Table 2. The formation energies of the $C_{2 v}$ complex in the $(0),(+1)$, and $(+2)$ charge states, see Figure $4 \mathrm{c}$, show that the $C_{2 v}(+2)$ complex dominates up to a Fermi level value of $0.37 \mathrm{eV}$, almost coincident with a value of $0.383 \mathrm{eV}$ (the InAs energy gap restored by the formation of $C_{2 v}$ complexes). Therefore, the $C_{2 v}(+2)$ complex behaves as a shallow donor and can account for a band-filling effect when the $\mathrm{H}$ concentration is higher than that of $\mathrm{N}$ atoms.

Finally, we have considered the $\mathrm{H}_{\mathrm{bc}}-3 \mathrm{H}_{\mathrm{ab}}(0),(+1)$, and $(+2)$ complexes. At variance with the $\mathrm{GaAsN}$ case, the reaction leading to the formation of this complex is exothermic in all of the three charge states, see Table 2. However, the corresponding $\Delta E$ values are small or significantly lower than those of the $\mathrm{H}_{\mathrm{bc}}$ and $\mathrm{C}_{2 v}$ complexes. Thus, this complex plays a possible, minor role in InAsN. The formation energy graphs in Figure $4 \mathrm{~d}$ show that the $\varepsilon(+/ 0)$ and $\varepsilon(+2 / 0)$ values for this complex are both equal to $0.35 \mathrm{eV}$. However, both the neutral and the +2 charged complexes restore an InAs gap of $0.38 \mathrm{eV}$. Thus, this complex might not behave as a shallow donor.

Origin of the Energy Gap Recovery and of the $\mathrm{H}$ Shallow Donor Behavior. As a preliminary step, let us note that the $\mathrm{N}$ effects on the host band gap in III-V-N alloys have been explained by a band anticrossing model which identifies the reduction in energy gap as due to the interaction between the host matrix CBM and a band related mainly to single $\mathrm{N}$ atoms and $\mathrm{N}$ clusters resonant with the $\mathrm{CB} .{ }^{4,52-55}$ In the case of, for example, GaAsN, these resonant $\mathrm{N}$ states come from the $\mathrm{N}-\mathrm{Ga}$ interactions, and for an isolated $\mathrm{N}$, they receive significant contributions from electronic states of $\mathrm{N}$ and its four Ga nearest neighbors, spatially localized for about $50 \%$ on these five atoms. ${ }^{56}$ Thus, the $\mathrm{H}$-induced energy gap recovery, that is, the $\mathrm{N}$ neutralization induced by $\mathrm{H}$, has been simply attributed to the strong perturbations caused by the formation of $\mathrm{N}-\mathrm{H}$ complexes on $\mathrm{N}-\mathrm{Ga}$ interactions and on resonant $\mathrm{N}$ states. Within such an assumption, some theoretical studies on the $\mathrm{H}$ effects in GaAsN have just confirmed the energy gap recovery induced by $\mathrm{H}$ by distinguishing, at the same time, between $\mathrm{N}-\mathrm{H}$ complexes able or not able to cause such an effect. $^{4,16,23}$
Within this topic, as anticipated above, the present results raise two questions about: (i) the different ability to neutralize the $\mathrm{N}$ effect on the energy gap shown, in GaAsN and InAsN, by neutral and charged $\mathrm{N}-\mathrm{H}_{\mathrm{bc}}$ complexes sharing the same geometry, and (ii) the disappearance of such a difference in the case of multi-H complexes sharing, once more, the same geometry in the two alloys.

We propose a simple, qualitative model, which seems able to account for these peculiar results. This model has been inspired by the following considerations. First, in the case of $\mathrm{GaAsN}$, the breakage of just one $\mathrm{Ga}-\mathrm{N}$ bond, replaced by a $\mathrm{N}-\mathrm{H}_{\mathrm{bc}}$ one, is sufficient to neutralize the $\mathrm{N}$ effect and to fully recover the GaAs gap. In InAsN, instead, we need at least two In-N bonds to be broken, as in the case of the $C_{2 v}$ complexes. This suggests the existence of some relationship between changes of the $\mathrm{N}$ local, chemical environment, and the changes of the material band structure induced by the formation of a $\mathrm{N}-\mathrm{H}$ complex. Second, the breakage of cation $-\mathrm{N}$ bonds is expected to induce a significant rearrangement of the local atomic charges in the complex, which should involve mainly the $\mathrm{N}$ neighboring cations. In this regard, let us consider that when $\mathrm{N}$ is introduced, for example, in the GaAs lattice, the four Ga neighboring the $\mathrm{N}$ atom lose more electronic charge than their companions bonded to As atoms because the $\mathrm{N}$ electronegativity is higher than the As one. The atomic charge rearrangement following the formation of a $\mathrm{N}-\mathrm{H}$ complex could induce a recovery of the charge lost by the Ga cations neighboring the $\mathrm{N}$ atom. This would correspond to a weakening of the perturbation induced by $\mathrm{N}$ on its neighboring cations (the same cations contributing to the $\mathrm{N}$ resonant states), which seems reasonable to relate to the recovery of the energy gap. In this regard, as a final consideration, let us take this line of reasoning to the limit and note that if the formation of a $\mathrm{N}-\mathrm{H}$ complex led to a full recovery of the atomic charge for all of the four $\mathrm{Ga}$ atoms neighboring the $\mathrm{N}$ atom-as it would occur if $\mathrm{N}$ was substituted by an As atom-it would be quite reasonable to expect a full recovery of the GaAs energy gap.

Keeping in mind such considerations, we have investigated the changes induced by the formation of a $\mathrm{N}-\mathrm{H}$ complex on the atomic charges of the $\mathrm{Ga}$ or In atoms neighboring the $\mathrm{N}$ one. Atomic charges of these atoms in bulk GaAsN and InAsN and in the most representative $\mathrm{N}-\mathrm{H}$ complexes, accurately calculated by using the Bader method (see Theoretical Methods), are reported in Table 3.

For each complex, we have investigated the atomic charge rearrangement induced on the four cations surrounding the $\mathrm{N}$ 
atom by the formation of a given $\mathrm{N}-\mathrm{H}$ complex and compared the results achieved in GaAsN with the InAsN ones.

Let us start with the $\mathrm{N}-\mathrm{H}_{\mathrm{bc}}(0)$ complex in GaAsN. The results in Table 3 show that a Ga atom bonded to As atoms loses some electronic charge, by reducing its atomic charge from $13 e$ to $12.22 e$ (the outer $10 \mathrm{~d}$ electrons of a Ga or In atom are considered here as valence electrons). A Ga atom bonded to an isolated $\mathrm{N}$ atom further reduces its atomic charge to the value of $12.00 e$. Now, we focus on the.$x x$ fraction of a 12.xxe cation charge and investigate how much the formation of a N$\mathrm{H}$ complex permits to recover some atomic charge on the cations involved in the complex; we use, as a reference value, $0.22 e$, that is the fraction for a (bulk) Ga bonded to an As atom in GaAsN. With this purpose, we define $R$ as the ratio between the.$x x$ fraction of the charge relative to the complex we are interested in with respect to the reference value, $0.22 \mathrm{e}$. Values of $R$ are given in Table 3, while a pictorial representation of such a quantity is given in Figure 5.

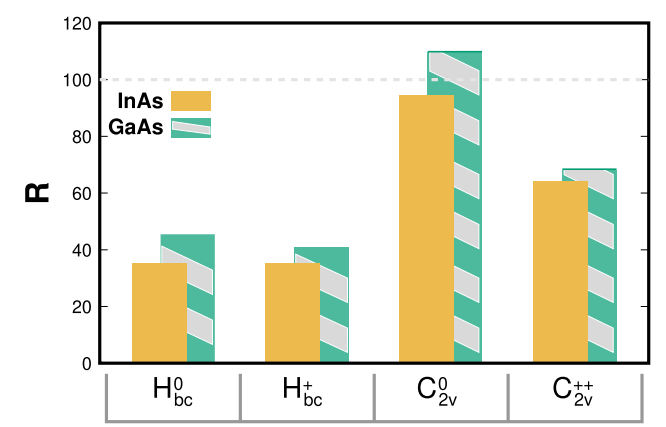

Figure 5. $R$ factor (see text) obtained from the Bader charges reported in Table 3.

In detail, the mean value of the atomic charge for the four $\mathrm{Ga}$ atoms involved in the $\mathrm{N}-\mathrm{H}_{\mathrm{bc}}(0)$ complex, turns out to be 12.10e. Then, we consider the ratio between the fractions of $0.10 e$ and $0.22 e$, which is equal to $45 \%$, as indicated in Table 3 and Figure 5. Such a partial recovery of atomic charge corresponds to a full recovery of the host energy gap in GaAsN, see Figure 2. When the same analysis is conducted for the corresponding complex in InAsN, the In charge recovery is equal to $35 \%$, turning out in a limited reopening that does not reach a complete recovery of the InAs gap. In the case of the charged complex, the charge recovery is $43 \%$ in GaAsN and $34 \%$ in InAsN. Once more, we have full recovery of the energy gap only in the presence of a higher recovery of the cation charge. The value of about $45 \%$ seems to be a sort of lower bound. Below that value of charge recovery, the energy gap reopening is incomplete. On the other hand, both neutral and charged $C_{2 v}$ complexes show a quite high recovery of atomic charge, for example, 68 and $64 \%$, for the Ga and In atoms involved in the $C_{2 v}(+2)$ complex, respectively, and recover the host energy gap both in GaAsN and InAsN. The $\mathrm{H}_{b c}-3 \mathrm{H}_{\mathrm{ab}}$ complexes show similar trends.

The above results permit to formulate a model that deepens our understanding of the $\mathrm{H}$-induced $\mathrm{N}$ neutralization by showing that an explanation of such a $\mathrm{H}$ effect can be founded on: (i) the existence of a direct relationship between the energy gap recovery caused by the formation of a $\mathrm{N}-\mathrm{H}$ complex and the recovery of the atomic charge of the Ga-In cations neighboring the $\mathrm{N}$ impurity. More specifically, a gradual increase of the atomic charge of those Ga (or In) atoms, induced by the complex formation, can be considered as a signal of the progressive weakening of the perturbations caused by $\mathrm{N}$ on its host environment, which culminates with the $\mathrm{N}$ neutralization (indeed, even in the case of missed recovery, as found for the $\mathrm{N}-\mathrm{H}_{\mathrm{bc}}$ complexes, an increase of the In atomic charge accompanies a partial InAsN gap reopening); (ii) a change of perspective, where the attention moves from what happens to the resonant $\mathrm{N}$ states to what happens to the local properties of the Ga (or In) atoms next to $\mathrm{N}$ after the formation of the complex; and (iii) a larger effectiveness of charge recovery of the Ga cations with respect to the In ones, which can be immediately related to a Ga electronegativity larger than the In one.

Our model easily explains the different (comparable) ability shown above by a same single-H (multi-H) complex in the occurrence of the neutralization of $\mathrm{N}$ in GaAsN and InAsN. In the former alloy, a more effective charge recovery is indeed accounted for by the fact that $\mathrm{Ga}$ atoms, more electronegative than the In ones, take a larger advantage even by the breakage of just one $\mathrm{N}$-cation bond. The ensuing atomic charge recovery is sufficient to achieve the neutralization of the $\mathrm{N}$ effects on the GaAsN energy gap. The breakage of two Ncation bonds is needed, instead, to achieve the same effect in InAsN. As an overall indication given by the model, the different electronegativity of the $\mathrm{Ga}$ and In cations, that is, the different local, chemical environment of the $\mathrm{N}-\mathrm{H}$ complexes, can account for the different ability of $\mathrm{H}$ to recover the energy gap in the two alloys.

At this point, we can come back to consider a feature of the results regarding the $\mathrm{N}-\mathrm{H}_{\mathrm{bc}}$ complexes, which can be clarified by taking into account the overall results produced by the Bader charge analysis. In the case of these complexes, the difference between the percentages of atomic charge recovery of Ga cations, $45 \%$, and In cations, 35\%, may appear too small for justifying the occurrence of energy gap recovery only in the case of complexes formed by Ga cations. However, let us note that, significantly, even just the break of one $\mathrm{In}-\mathrm{N}$ bond and the subsequent, small charge recovery percentage induce a noticeable reopening of the InAsN energy gap of more than $50 \%$ (see Figure 2, bottom panel). Thus, in the case of $\mathrm{Ga}$ cations-which have a larger electronegativity than the In ones and are more effective in the recovery of atomic charge, as shown by the results in Table 3-it seems well-founded that the break of just one $\mathrm{Ga}-\mathrm{N}$ bond, and a small increase of the charge recovery induce a larger effect than in the In-N case, thus leading from a partial to a full reopening of the energy gap. This argument is further supported by a classic work, ${ }^{57}$ where Kurtin et al. have shown that the difference in electronegativity between the atoms that build up a semiconductor may lead to abrupt changes in some of the relevant physical observables of the system, such as, for instance, the relative strength in exciton absorbance, see Figure 2 in the mentioned paper. Accordingly, in the present case, we propose that changes in the band gap related to changes in the cation electronegativity belong to the same class of phenomena, showing a nonlinear behavior that leads to noticeable differences in the band gap recovery when passing from $35 \%$ of charge recovery to $45 \%$.

The results in Table 3 also indicate that, as occurring, for instance, in the case of the neutral $\mathrm{N}-\mathrm{H}_{\mathrm{bc}}$ complex, the extra electron introduced by the $\mathrm{H}$ atom is accommodated in appreciable, but different portions on the involved $\mathrm{Ga}$ or In atoms, about 40 and $27 \%$, respectively, slightly involving the $\mathrm{N}$ 
atom. This result-and the fact that the extra electrons introduced by $\mathrm{H}$ atoms are accommodated in defect states within the energy gap in GaAsN, whereas they occupy the $\mathrm{CBM}$ in InAsN (see Figure 2) - can be immediately related to the different tendency to attract electrons of the $\mathrm{Ga}$ and In atoms. In turn, both results suggest that the different electronegativity of $\mathrm{Ga}$ and $\mathrm{In}$ atoms is also at the origin of the shallow donor behavior, shown by $\mathrm{N}-\mathrm{H}$ complexes, that is, they easily lose their extra electrons, only in InAsN, and not in GaAsN.

\section{CONCLUSIONS}

In this work, we address theoretically the opposite behaviors of atomic hydrogen in two related III-V-N alloys: GaAsN and InAsN. Experimentally, it was observed that in GaAsN, hydrogen passivates the $\mathrm{N}$ electronic activity (with an ensuing recovery of the GaAs band gap), without contributing extra electrons to the conduction band (i.e., $\mathrm{H}$ incorporation does not lead to band-filling effects). Opposite behaviors were found in InAsN, where hydrogen does not induce a recovery of the InAs gap and behaves as a shallow donor.

We used DFT-HSE calculations in a supercell approach to pinpoint the role played by $\mathrm{N}-\mathrm{H}$ complexes and the underlying electronic structure of the GaAsN and InAsN hosts with regard to the findings reported above. First, we analyzed the effects of the most stable $\mathrm{N}-\mathrm{H}$ complexes on the band gap energy. We found that both single- and multi- $\mathrm{H}$ complexes neutralize the $\mathrm{N}$ effects in GaAsN, by fully recovering the GaAs energy gap, in agreement with the experiments. In InAsN, on the other hand, single $\mathrm{N}-\mathrm{H}$ complexes only increase the energy gap without inducing a full recovery of the InAs one, consistently with available experimental data. The formation of multi- $\mathrm{H}$ complexes is instead required to neutralize $\mathrm{N}$ in $\operatorname{InAsN}$, thus indicating that different hydrogen incorporation conditions have to be explored to achieve full $\mathrm{N}$ passivation. Second, present results showed that no shallow donor states stem from single- and multiple-H complexes in GaAsN, while the opposite is true in InAsN, in agreement with optical and transport studies.

The results regarding the neutralization of the effects of $\mathrm{N}$ were somewhat surprising because both single- and multi-H complexes share a same geometry in GaAsN and InAsN, and therefore, they are expected to perturb the $\mathrm{N}$ properties in a quite similar way. On the contrary, single- $\mathrm{H}$ complexes neutralize the $\mathrm{N}$ effects in $\mathrm{GaAsN}$, not in InAsN, while multi-H complexes neutralize $\mathrm{N}$ in both alloys. Stimulated by such issues, we have found that these results can be accounted for by a simple model which also fully explains the different $\mathrm{H}$ effectiveness in recovering the GaAs and InAs energy gaps. In this model, the energy gap recovery is directly related to a recovery of the atomic charge of the $\mathrm{Ga} / \mathrm{In}$ cations neighboring the $\mathrm{N}$ impurity in a $\mathrm{N}-\mathrm{H}$ complex. More specifically, a gradual restoration of the $\mathrm{Ga}-\mathrm{In}$ atomic charge can be considered as a signal of progressive weakening of the perturbations caused by $\mathrm{N}$ on its host environment, which culminates with the $\mathrm{N}$ neutralization. A larger extent of charge recovery is found for the Ga cations with respect to the In ones, which explains the different (comparable) effectiveness in neutralizing the $\mathrm{N}$ effects shown by single-H (multi-H) complexes. The different effectiveness of the $\mathrm{Ga}$ and In cations to recover atomic charge can be immediately related to their different electronegativity, larger for Ga than for In, which, therefore, also thoroughly accounts for the different ability of $\mathrm{H}$ to neutralize the $\mathrm{N}$ effects in the two alloys. Remarkably, even the differences concerning the $\mathrm{H}$ shallow donor behavior in the two alloys can be related to the different electronegativity of the two cations.

The different tendency to attract electrons of the Ga and In atoms becomes, therefore, a unifying feature at the origin of the different occurrence of the two main effects of $\mathrm{H}$ (bandgap reopening vs shallow donor formation) in the GaAsN and InAsN alloys. Finally, we point out that the comprehension of the $\mathrm{H}$ properties in these alloys turns out to be particularly relevant in InGaAsN (substantially a derivative of the GaAsN and InAsN alloys), an important material for technological applications. In this regard, we can anticipate some results of a theoretical investigation we recently performed on the $\mathrm{H}$ effects in this alloy. These novel results substantially agree with the present ones: multi-H complexes neutralize the $\mathrm{N}$ effects, while the $\mathrm{In}-\mathrm{H}_{\mathrm{bc}}-\mathrm{N}$ ones do not. As an exception, also the $\mathrm{Ga}-\mathrm{H}_{\mathrm{bc}}-\mathrm{N}$ complexes do not restore the host energy gap. All together, these results fully agree with those reported in two previous papers, ${ }^{58,59}$ showing that the recovery of the InGaAs energy gap is achieved only by forming di-hydrogen complexes, while $\mathrm{N}-\mathrm{H}_{\mathrm{bc}}$ complexes do not produce such an effect.

\section{AUTHOR INFORMATION}

\section{Corresponding Author}

Francesco Filippone - Istituto di Struttura della Materia-CNR (ISM-CNR), I-00016 Montelibretti, Italy; ○ orcid.org/00000001-5862-1115; Email: francesco.filippone@ism.cnr.it

\section{Authors}

Giuseppe Mattioli - Istituto di Struttura della Materia-CNR (ISM-CNR), I-00016 Montelibretti, Italy; ○ orcid.org/00000001-6331-198X

Antonio Polimeni - Dipartimento di Fisica and CNISM, Sapienza Università di Roma, I-00185 Roma, Italy; () orcid.org/0000-0002-2017-4265

Marco Felici - Dipartimento di Fisica and CNISM, Sapienza Università di Roma, I-00185 Roma, Italy

Aldo Amore Bonapasta - Istituto di Struttura della MateriaCNR (ISM-CNR), I-00016 Montelibretti, Italy

Complete contact information is available at:

https://pubs.acs.org/10.1021/acs.jpcc.0c05098

\section{Notes}

The authors declare no competing financial interest.

\section{REFERENCES}

(1) Pavesi, L.; Giannozzi, P. Atomic and molecular hydrogen in gallium arsenide: A theoretical study. Phys. Rev. B: Condens. Matter Mater. Phys. 1992, 46, 4621-4629.

(2) Bonapasta, A. A.; Pavesi, L. Hydrogen interaction with shallow and deep centers in GaAs. Int. J. Quantum Chem. 1996, 57, 823-841.

(3) Van de Walle, C. G.; Neugebauer, J. Universal alignment of hydrogen levels in semiconductors, insulators and solutions. Nature 2003, 423, 626-628.

(4) Hydrogenated Dilute Nitride Semiconductors; Ciatto, G., Ed.; Pan Stanford: Penthouse Level, Suntec Tower 3, 8 Temasek Boulevard Singapore, 2015.

(5) Albo, A.; Fekete, D.; Bahir, G. The opportunity of using InGaAsN/AlGaAs quantum wells for extended short-wavelength infrared photodetection. Infrared Phys. Technol. 2019, 96, 68-76.

(6) Felici, M.; Polimeni, A.; Salviati, G.; Lazzarini, L.; Armani, N.; Masia, F.; Capizzi, M.; Martelli, F.; Lazzarino, M.; Bais, G.; et al. InPlane Bandgap Engineering by Modulated Hydrogenation of Dilute Nitride Semiconductors. Adv. Mater. 2006, 18, 1993-1997. 
(7) Birindelli, S.; Felici, M.; Wildmann, J. S.; Polimeni, A.; Capizzi, M.; Gerardino, A.; Rubini, S.; Martelli, F.; Rastelli, A.; Trotta, R. Single Photons on Demand from Novel Site-Controlled GaAsN/ GaAsN:H Quantum Dots. Nano Lett. 2014, 14, 1275-1280.

(8) Pettinari, G.; Felici, M.; Biccari, F.; Capizzi, M.; Polimeni, A. Site-Controlled Quantum Emitters in Dilute Nitrides and their Integration in Photonic Crystal Cavities. Photonics 2018, 5, 10.

(9) Biccari, F.; Boschetti, A.; Pettinari, G.; La China, F.; Gurioli, M.; Intonti, F.; Vinattieri, A.; Sharma, M.; Capizzi, M.; Gerardino, A.; et al. Site-Controlled Single-Photon Emitters Fabricated by NearField Illumination. Adv. Mater. 2018, 30, 1705450.

(10) Felici, M.; Pettinari, G.; Biccari, F.; Boschetti, A.; Younis, S.; Birindelli, S.; Gurioli, M.; Vinattieri, A.; Gerardino, A.; Businaro, L.; et al. Broadband enhancement of light-matter interaction in photonic crystal cavities integrating site-controlled quantum dots. Phys. Rev. B 2020, 101, 205403.

(11) Kozlova, N. V.; Pettinari, G.; Makarovsky, O.; Mori, N.; Polimeni, A.; Capizzi, M.; Zhuang, Q. D.; Krier, A.; Patanè, A. Nonresonant hydrogen dopants in In(AsN): A route to high electron concentrations and mobilities. Phys. Rev. B: Condens. Matter Mater. Phys. 2013, 87, 165207.

(12) Xu, L.; Patel, D.; Menoni, C. S.; Pikal, J. M.; Yeh, J.; Huang, J. Y. T.; Mawst, L. J.; Tansu, N. Carrier Recombination Dynamics Investigations of Strain-Compensated InGaAsN Quantum Wells. IEEE Photonics J. 2012, 4, 2382-2389.

(13) Birindelli, S.; Kesaria, M.; Giubertoni, D.; Pettinari, G.; Velichko, A. V.; Zhuang, Q. D.; Krier, A.; Patanè, A.; Polimeni, A.; Capizzi, M. Peculiarities of the hydrogenated $\operatorname{In}($ AsN) alloy. Semicond. Sci. Technol. 2015, 30, 105030.

(14) Alvarez, J.; Kleider, J.-P.; Trotta, R.; Polimeni, A.; Capizzi, M.; Martelli, F.; Mariucci, L.; Rubini, S. Giant and reversible enhancement of the electrical resistance of $\mathrm{GaAs}_{1-\mathrm{x}} \mathrm{N}_{\mathrm{x}}$ by hydrogen irradiation. Phys. Rev. B: Condens. Matter Mater. Phys. 2011, 84, 085331.

(15) Kim, Y.-S.; Chang, K. J. Nitrogen-monohydride versus nitrogen-dihydride complexes in GaAs and $\mathrm{GaAs}_{1-\mathrm{x}} \mathrm{N}_{\mathrm{x}}$ alloys. Phys. Rev. B: Condens. Matter Mater. Phys. 2002, 66, 073313.

(16) Janotti, A.; Zhang, S. B.; Wei, S.-H.; Van de Walle, C. G. Effects of Hydrogen on the Electronic Properties of Dilute GaAsN Alloys. Phys. Rev. Lett. 2002, 89, 086403.

(17) Bonapasta, A. A.; Filippone, F.; Giannozzi, P.; Capizzi, M.; Polimeni, A. Structure and Passivation Effects of Mono- and Dihydrogen Complexes in $\mathrm{GaAs}_{\mathrm{y}} \mathrm{N}_{1-\mathrm{y}}$ Alloys. Phys. Rev. Lett. 2002, $89,216401$.

(18) Bonapasta, A. A.; Filippone, F.; Giannozzi, P. Nitrogen passivation by atomic hydrogen in $\mathrm{GaAs}_{\mathrm{y}} \mathrm{N}_{1-\mathrm{y}}$ and $\mathrm{In}_{\mathrm{x}} \mathrm{Ga}_{1-\mathrm{x}} \mathrm{As}_{\mathrm{y}} \mathrm{N}_{1-\mathrm{y}}$ alloys. Phys. Rev. B: Condens. Matter Mater. Phys. 2003, 68, 115202.

(19) Fowler, W. B.; Martin, K. R.; Washer, K.; Stavola, M. Structure and vibrational properties of $\mathrm{N}-\mathrm{H}_{2}$ complexes in GaAs:N. Phys. Rev. B: Condens. Matter Mater. Phys. 2005, 72, 035208.

(20) Du, M.-H.; Limpijumnong, S.; Zhang, S. B. Hydrogen pairs and local vibrational frequencies in $\mathrm{H}$-irradiated $\mathrm{GaAs}_{1-\mathrm{y}} \mathrm{N}_{\mathrm{y}}$. Phys. Rev. B: Condens. Matter Mater. Phys. 2005, 72, 073202.

(21) Kleekajai, S.; Jiang, F.; Colon, K.; Stavola, M.; Fowler, W. B.; Martin, K. R.; Polimeni, A.; Capizzi, M.; Hong, Y. G.; Xin, H. P.; et al. Vibrational properties of the H-N-H complex in dilute III-N-V alloys: Infrared spectroscopy and density functional theory. Phys. Rev. B: Condens. Matter Mater. Phys. 2008, 77, 085213.

(22) Wen, L.; Bekisli, F.; Stavola, M.; Fowler, W. B.; Trotta, R.; Polimeni, A.; Capizzi, M.; Rubini, S.; Martelli, F. Detailed structure of the $\mathrm{H}-\mathrm{N}-\mathrm{H}$ center in $\mathrm{GaAs}_{\mathrm{y}} \mathrm{N}_{1-\mathrm{y}}$ revealed by vibrational spectroscopy under uniaxial stress. Phys. Rev. B: Condens. Matter Mater. Phys. 2010, $81,233201$.

(23) Bonapasta, A. A.; Filippone, F.; Mattioli, G. H-Induced Dangling Bonds in $\mathrm{H}-$-Isoelectronic-Impurity Complexes Formed in $\mathrm{GaAs}_{1-\mathrm{y}} \mathrm{N}_{\mathrm{y}}$ Alloys. Phys. Rev. Lett. 2007, 98, 206403.

(24) Xin, H. P.; Tu, C. W.; Geva, M. Annealing behavior of p-type Ga0.892In0.108NxAs1-x $(0 \leq \mathrm{X} \leq 0.024)$ grown by gas-source molecular beam epitaxy. Appl. Phys. Lett. 1999, 75, 1416-1418.
(25) Xin, H. P.; Tu, C. W.; Geva, M. Effects of hydrogen on doping of GaInNAs grown by gas-source molecular beam epitaxy. J. Vac. Sci. Technol., B: Microelectron. Nanometer Struct.-Process., Meas., Phenom. 2000, 18, 1476-1479.

(26) Heyd, J.; Scuseria, G. E.; Ernzerhof, M. Hybrid functionals based on a screened Coulomb potential. J. Chem. Phys. 2003, 118, 8207.

(27) Chen, W.; Pasquarello, A. First-principles determination of defect energy levels through hybrid density functionals andGW. J. Phys.: Condens. Matter 2015, 27, 133202.

(28) Heyd, J.; Scuseria, G. E.; Ernzerhof, M. Hybrid functionals based on a screened Coulomb potential. J. Chem. Phys. 2003, 118, $8207-8215$.

(29) Giannozzi, P.; Andreussi, O.; Brumme, T.; Bunau, O.; Buongiorno Nardelli, M.; Calandra, M.; Car, R.; Cavazzoni, C.; Ceresoli, D.; Cococcioni, M.; et al. Advanced capabilities for materials modelling with Quantum ESPRESSO. J. Phys.: Condens. Matter 2017, 29,465901 .

(30) Giannozzi, P.; Baroni, S.; Bonini, N.; Calandra, M.; Car, R.; Cavazzoni, C.; Ceresoli, D.; Chiarotti, G. L.; Cococcioni, M.; Dabo, I.; et al. QUANTUM ESPRESSO: a modular and open-source software project for quantum simulations of materials. J. Phys.: Condens. Matter 2009, 21, 395502.

(31) Hamann, D. R. Optimized norm-conserving Vanderbilt pseudopotentials. Phys. Rev. B: Condens. Matter Mater. Phys. 2013, 88,085117

(32) Tanner, D. S. P.; Caro, M. A.; Schulz, S.; O’Reilly, E. P. Hybrid functional study of nonlinear elasticity and internal strain in zincblende III-V materials. Phys. Rev. Mater. 2019, 3, 013604.

(33) Böer, K. W.; Pohl, U. W. Semiconductor Physics; Springer International Publishing: Cham, 2018; pp 243-302.

(34) Ibáñez, J.; Oliva, R.; De la Mare, M.; Schmidbauer, M.; Hernández, S.; Pellegrino, P.; Scurr, D. J.; Cuscó, R.; Artús, L.; Shafi, M.; et al. Structural and optical properties of dilute InAsN grown by molecular beam epitaxy. J. Appl. Phys. 2010, 108, 103504.

(35) Tisch, U.; Finkman, E.; Salzman, J. The anomalous bandgap bowing in GaAsN. Appl. Phys. Lett. 2002, 81, 463-465.

(36) Gallino, F.; Pacchioni, G.; Di Valentin, C. Transition levels of defect centers in $\mathrm{ZnO}$ by hybrid functionals and localized basis set approach. J. Chem. Phys. 2010, 133, 144512.

(37) Di Valentin, C.; Pacchioni, G. Spectroscopic Properties of Doped and Defective Semiconducting Oxides from Hybrid Density Functional Calculations. Acc. Chem. Res. 2014, 47, 3233-3241.

(38) Bader, R. F. W. A quantum theory of molecular structure and its applications. Chem. Rev. 1991, 91, 893-928.

(39) Bader, R. F. W. Atoms in Molecules. A Quantum Theory; Clarendon Press: Oxford, U.K., 1994.

(40) Kresse, G.; Hafner, J. Ab initio molecular dynamics for liquid metals. Phys. Rev. B: Condens. Matter Mater. Phys. 1993, 47, 558-561.

(41) Kresse, G.; Hafner, J. Ab initio molecular-dynamics simulation of the liquid-metal-amorphous-semiconductor transition in germanium. Phys. Rev. B: Condens. Matter Mater. Phys. 1994, 49, 1425114269.

(42) Kresse, G.; Furthmüller, J. Efficient iterative schemes for ab initio total-energy calculations using a plane-wave basis set. Phys. Rev. B: Condens. Matter Mater. Phys. 1996, 54, 11169-11186.

(43) Kresse, G.; Joubert, D. From ultrasoft pseudopotentials to the projector augmented-wave method. Phys. Rev. B: Condens. Matter Mater. Phys. 1999, 59, 1758-1775.

(44) Kresse, G.; Hafner, J. Norm-conserving and ultrasoft pseudopotentials for first-row and transition elements. J. Phys.: Condens. Matter 1994, 6, 8245-8257.

(45) Kresse, G.; Furthmüller, J. Efficiency of ab-initio total energy calculations for metals and semiconductors using a plane-wave basis set. Comput. Mater. Sci. 1996, 6, 15-50.

(46) Tang, W.; Sanville, E.; Henkelman, G. A grid-based Bader analysis algorithm without lattice bias. J. Phys.: Condens. Matter 2009, 21,084204 
(47) Vurgaftman, I.; Meyer, J. R. Band parameters for nitrogencontaining semiconductors. J. Appl. Phys. 2003, 94, 3675-3696.

(48) De Luca, M.; Pettinari, G.; Ciatto, G.; Amidani, L.; Filippone, F.; Polimeni, A.; Fonda, E.; Boscherini, F.; Bonapasta, A. A.; Giubertoni, D.; et al. Identification of four-hydrogen complexes in In-rich $\operatorname{In}_{x} \mathrm{Ga}_{1-\mathrm{x}} \mathrm{N}(\mathrm{x}>0.4)$ alloys using photoluminescence, $\mathrm{x}$-ray absorption, and density functional theory. Phys. Rev. B: Condens. Matter Mater. Phys. 2012, 86, 201202.

(49) Pettinari, G.; Filippone, F.; Polimeni, A.; Mattioli, G.; Patanè, A.; Lebedev, V.; Capizzi, M.; Amore Bonapasta, A. Genesis of "Solitary Cations" Induced by Atomic Hydrogen. Adv. Funct. Mater. 2015, 25, 5353-5359.

(50) Buda, F.; Chiarotti, G. L.; Car, R.; Parrinello, M. Proton diffusion in crystalline silicon. Phys. Rev. Lett. 1989, 63, 294-297.

(51) Klar, P. J.; Grüning, H.; Güngerich, M.; Heimbrodt, W.; Koch, J.; Torunski, T.; Stolz, W.; Polimeni, A.; Capizzi, M. Global changes of the band structure and the crystal lattice of $\mathrm{Ga}(\mathrm{N}, \mathrm{As})$ due to hydrogenation. Phys. Rev. B: Condens. Matter Mater. Phys. 2003, 67, 121206.

(52) Kent, P. R. C.; Zunger, A. Evolution of III-V Nitride Alloy Electronic Structure: The Localized to Delocalized Transition. Phys. Rev. Lett. 2001, 86, 2613-2616.

(53) O’Reilly, E. P.; Lindsay, A.; Klar, P. J.; Polimeni, A.; Capizzi, M. Trends in the electronic structure of dilute nitride alloys. Semicond. Sci. Technol. 2009, 24, 033001.

(54) Shan, W.; Walukiewicz, W.; Ager, J. W.; Haller, E. E.; Geisz, J. F.; Friedman, D. J.; Olson, J. M.; Kurtz, S. R. Band Anticrossing in GaInNAs Alloys. Phys. Rev. Lett. 1999, 82, 1221-1224.

(55) Pettinari, G.; Polimeni, A.; Masia, F.; Trotta, R.; Felici, M.; Capizzi, M.; Niebling, T.; Stolz, W.; Klar, P. J. Electron Mass in Dilute Nitrides and its Anomalous Dependence on Hydrostatic Pressure. Phys. Rev. Lett. 2007, 98, 146402.

(56) Lindsay, A.; O’Reilly, E. P. Influence of nitrogen resonant states on the electronic structure of GaNxAs1-x. Solid State Commun. 2001, $118,313-317$.

(57) Kurtin, S.; McGill, T. C.; Mead, C. A. Fundamental Transition In The Electronic Nature Of Solids. Phys. Rev. Lett. 1969, 22, 14331436.

(58) Mou, T.; Li, S.; Brown, C. R.; Whiteside, V. R.; Hossain, K.; Al Khalfioui, M.; Leroux, M.; Sellers, I. R.; Wang, B. Role of In in Hydrogenation of N-Related Complexes in GaInNAs. ACS Appl. Electron. Mater. 2019, 1, 461-466.

(59) Brown, C. R.; Estes, N. J.; Whiteside, V. R.; Wang, B.; Hossain, K.; Golding, T. D.; Leroux, M.; Al Khalfioui, M.; Tischler, J. G.; Ellis, C. T.; et al. The effect and nature of $\mathrm{N}-\mathrm{H}$ complexes in the control of the dominant photoluminescence transitions in UV-hydrogenated GaInNAs. RSC Adv. 2017, 7, 25353-25361. 